\title{
Correction: DPH1 syndrome: two novel variants and structural and functional analyses of seven missense variants identified in syndromic patients
}

\author{
Roser Urreizti ${ }^{1} \cdot$ Klaus Mayer $^{2} \cdot$ Gilad D. Evrony $^{3} \cdot$ Edith Said $^{4,5} \cdot$ Laura Castilla-Vallmanya $^{1} \cdot$ Neal A. L. Cody ${ }^{6,7}$. \\ Guillem Plasencia $^{8} \cdot$ Bruce D. Gelb $\mathbb{1}^{6,9,10} \cdot$ Daniel Grinberg $\mathbb{D}^{1} \cdot$ Ulrich Brinkmann ${ }^{2} \cdot$ Bryn D. Webb $b^{6,9,10}$. \\ Susanna Balcells ${ }^{1}$
}

Published online: 12 April 2019

(c) European Society of Human Genetics 2019

\section{Correction to: Eur J Human Genet;}

https://doi.org/10.1038/s41431-019-0374-9;

published online 15 March 2019
Following the publication of the article, it was noted that the last column in Table 1, the total \% should have read 5/8 (62.5) for the 'Epilepsy' row, and not 5.7 (71.4). This has now been amended in the HTML and PDF of the original article.
These authors contributed equally: Roser Urreizti, Klaus Mayer, Gilad D. Evrony

These authors jointly supervised this work: Ulrich Brinkmann, Bryn D. Webb, Susanna Balcells

The original article can be found online at https://doi.org/10.1038/ s41431-019-0374-9.

\section{Roser Urreizti}

roseruf@yahoo.es

1 Department of Genetics, Microbiology and Statistics, Faculty of Biology, University of Barcelona, IBUB, IRSJD, CIBERER, Barcelona, Spain

2 Roche Pharma Research and Early Development. Large Molecule Research, Roche Innovation Center, Munich, Nonnenwald 2, 82377 Penzberg, Germany

3 Center for Human Genetics and Genomics, New York University Langone Health, New York, NY, USA

4 Section of Medical Genetics, Mater dei Hospital, Msida, Malta
5 Department of Anatomy and Cell Biology, University of Malta, Msida, Malta

6 Department of Genetics and Genomic Sciences, Icahn School of Medicine at Mount Sinai, New York, NY, USA

7 Sema4, Stamford, CT, USA

8 Lead Molecular Design, S.L, Sant Cugat del Vallés, Spain

9 Mindich Child Health and Development Institute, Icahn School of Medicine at Mount Sinai, New York, NY, USA

10 Department of Pediatrics, Icahn School of Medicine at Mount Sinai, New York, NY, USA 